\title{
CONTENT OF FORMATION OF OCCUPATIONAL SAFETY CULTURE OF FUTURE OCCUPATIONAL SAFETY AND HEALTH ENGINEERS
}

\author{
Elviza Abiltarova \\ Candidate of Pedagogical Sciences, Associate Professor, Institute of Vocational Education \\ and Training of the National Academy of Pedagogical Sciences of Ukraine, Ukraine \\ e-mail: elviza2008@gmail.com,orcid.org/0000-0001-9747-3303
}

Monika Fiksat

MSN, Polonia University in Czestochowa, Interdisciplinary Faculty, Poland e-mail: mfiksat@ap.edu.pl,orcid.org/0000-0002-6469-3876

\section{Summary}

The article is devoted to the problem of the formation of the culture of occupational safety among future occupational safety and health engineers. The importance of the selection of the content by taking into account the structural components of the occupational safety culture and the types of professional activities of an occupational safety engineer has been determined. The paper substantiates the content of formation of the safety culture of professional activity that includes: labor protection, organizational and managerial, legal, ergonomic, health-preserving and communicative components. It was established that the labor protection component should be implemented through a complex of professionally oriented academic disciplines in the field of labor protection; organizational and managerial component should be actualized through the content of the "Occupational Safety Management" academic course; legal component should be implemented through the course of "Legislative and Regulatory Concepts of Safety", ergonomic component should be realized through "Workplace Ergonomics" and "Occupational Safety Psychology" courses; health-preserving component should be revealed through "Medical and Biological Basics of Safety"; communicative component should be implemented through "Business Communications" and "Pedagogy of Safety" academic disciplines. The article uses theoretical and empirical research methods i.e. the analysis of pedagogical literature and dissertation researches on the problem of structuring the content of education and the safety culture formation, the analysis of curricula and basic educational programs in order to select disciplines aimed at the formation of the safety culture, the survey of labor protection specialists and the analysis of regulatory legal acts to identify the types of professional activities of an occupational safety engineer. It is concluded that it is necessary to develop a special course of "Occupational Safety Culture" for the Master's educational qualification level.

Keywords: vocational training, content structuring, occupational safety culture, health culture, labor culture, general culture.

\section{DOI https://doi.org/10.23856/3918}

\section{Introduction}

An important stage in the professional training of specialists of any area is designing the content of education which, according to most scientists, is defined as a system of knowledge, skills, professional experience, professional and personal qualities, the mastering of which contributes to the intellectual, social, comprehensive, spiritual development of individual. The analysis of scientific and pedagogical literature showed that the theoretical foundations of 
the content of education were laid by Yu. Babansky, A. Belyaeva, N. Bryukhanova, S. Goncharenko, V. Kraevsky, E. Kovalenko, V. Lednev, I. Lerner, M. Skatkin, V. Radkevich, N. Nichkalo, A. Khutorsky. In addition, numerous studies on the formation and development of safety culture, life safety culture, personal safety culture among preschoolers, schoolchildren, students (V. Akimov, E. Ayubov, T. Belykh, V. Berezutsky, Y. Vorobiev, V. Gafner, I. Golubeva, L. Gorina, V. Devisilov, S. Dembitskaya, V. Demyanchuk, S. Degtyarev, A. Dronov, R. Durnev, V. Evteev, M. Zorina, T. Zyryanova, I. Iovenko, A Kazmina, P. Kaigorodov, S. Kosynkina, V. Kuznetsov, N. Kulalaeva, V. Mashin, A. Mikhailov, L. Mossoulina, V. Moshkin, I. Nemkova, T. Petukhova, Yu. Repin, U. Sagaidak, V. Sapronov, A. Snegirev, T. Suvorova, N. Tverdokhlebov, O. Tretyakov) demonstrate the multidimensionality and diversity of approaches. Nevertheless, issues related to the selection and structuring of the content of formation of the safety culture among future specialists responsible for occupational safety and health at work and who are the main managers for the development of the safety culture among personnel require a deeper and more detailed study. In view of the above provisions, the purpose of the article is to substantiate and design the content of formation of the occupational safety culture (OSC) of future engineers for labor protection.

\section{Requirements for structuring content}

In the process of designing content, it was important to define the requirements for its structuring. So, in the course of the dissertation research, we proceeded from the structural components of the safety culture of professional activity that we had identified. On the basis of a theoretical analysis of scientific, pedagogical, psychological literature, and the results of the questionnaire survey of experts, we have established that the culture of professional activity safety of an occupational safety and health engineer is an integral quality of a specialist's personality, expressed by a combination of professional knowledge, skills, professional and personal qualities in the prevention of accidents at work and occupational diseases; including general culture, culture of labor protection, culture of health, culture of labor; manifested by a motivational-value attitude towards personal safety and the safety of the whole team, a careful attitude towards health and life; characterized by a high degree of responsibility, self-organization and self-development. The foregoing emphasizes the need to select a set of knowledge, skills and abilities aimed at the formation of general culture, the culture of labor protection, the culture of health, the culture of labor. In addition, an important condition for designing the content is its consistency with the functional responsibilities of the occupational safety and health engineer. Analysis of the Standard Regulations on the Labor Protection Service (2004), the results of a questionnaire and a survey of specialists in the field of labor protection of various enterprises allowed us to establish that the main activities of an occupational safety engineer are:

- organizational and managerial (designing and implementing of an occupational safety management system);

- standard-setting (development of regulatory support for the occupational safety management system);

- information and analytical (collecting, processing, analyzing and transferring the information on labor protection issues);

- preventive (ensuring the reduction of levels of occupational risks at the enterprise, taking into account working conditions, precaution and prevention of workplace injuries);

- monitoring (ensuring control over compliance with labor protection requirements and the state of working conditions at the workplace). Thus, taking into account the established requirements for the selection and structuring of the content, basing on the theoretical aspects 
of the study, we came to the conclusion that the content of the formation of the OSC of future occupational safety engineers is an interconnected system represented by the following components: labor protection, organizational and managerial, legal, ergonomic, health-preserving, communicative. Let's consider the content of each component in more detail.

\section{Content components of the occupational safety culture}

The pivot of the formation of the culture of labor protection as an integral element of the $\mathrm{OSC}$ is the labor protection component. The results of the analysis of the curricula of the Bachelor's degree course in specialty 263 "Civil Security" made it possible to establish that the labor protection component is implemented through the content of professionally oriented disciplines such as "Occupational Hygiene and Industrial Sanitation", "Electrical Safety", "Fire Safety" (or "Theory of Combustion"), "Attestation of Workplaces" (or "Examination of Working Conditions", "Investigation and Analysis of Accidents" (or "Prevention of Industrial Injuries"), "Control and Supervision in the Field of Safety" (or "Safety Monitoring"), "Occupational Risk Management", "Safety of Technological Processes", "Ventilation and Air Conditioning", "Document Management in the Field of Labor Protection". Consider the structuring of the above disciplines. Thus, the courses such as "Occupational Health and Industrial Sanitation", "Electrical Safety", "Fire Safety", "Safety of Technological Processes" provide for the presentation of systemic knowledge about the safe operation of electrical installations and methods of protection against electric shock; on the safe operation of buildings, constructions, industrial equipment from the standpoint of fire prevention and methods of fire protection system; the impact of harmful factors of the working environment on the human body and measures and means aimed at preventing their influence; hazards of the production process and equipment, and the requirements for the safe operation of equipment, tools and fixtures. The course of "Occupational Risk Management" broadens the horizons of students regarding methods and procedures for assessing the hazards and occupational risks of employees, providing benefits and compensation for work in harmful and hazardous working conditions. In addition, the course under consideration covers the requirements of regulatory and technical documentation for the operation of buildings, structures and production equipment. Please note that in the process of studying the above-mentioned disciplines, the following abilities must be formed: to identify various sources of danger in the production environment, work area; to determine hazard levels; to evaluate and analyze the nature of the interaction of the human body with hazards; to choose and apply the best methods and means of protection against hazards and occupational risks. The next discipline, "Investigation and Record of Accidents" lays down the skills to investigate accidents at work, in educational institutions, domestic accidents and occupational diseases. The main topics in the course of studying are methods of analyzing industrial injuries, the procedure for organizing the investigation of accidents, occupational diseases, industrial accidents, the procedure for investigating accidents that occurred during the educational process; the procedure for investigating accidents of a non-production nature; investigation materials; social protection of employees in case of industrial accidents and occupational diseases; the procedure for organizing medical examinations of employees of certain categories; the procedure for determining the degree of professional working capacity as a result of an industrial accident and occupational disease; organization of rehabilitation of the victim as a result of an industrial accident and occupational disease; statistical reporting on the state of industrial injuries. The discipline of "Safety Monitoring" or "Control and Supervision in the Field of Safety" is aimed at the formation of knowledge regarding the types, levels and methods of monitoring the 
state of labor conditions and safety; systems of state supervision and control over compliance with labor protection requirements; bodies of public control over labor protection; types of liability for violation of labor protection requirements; documentary support of control activities. Within the framework of the discipline of "Document Management in the Field of Labor Protection", the logistic channels for maintaining regulatory, administrative, reporting, statistical documentation on labor protection issues, as well as the procedure for information support in the field of labor protection that provides the receipt of external messages and the exchange of information between levels and functional structures of the organization.

One of the main types of professional activities of an occupational safety engineer is organizational and managerial that includes planning, development, implementation, maintenance, improvement, monitoring of the occupational safety management system at enterprises and organizations. We see the key condition for the formation of the culture of occupational safety as a structural component of the OCS in updating the content of education through the introduction of a special course such as "Occupational Safety Management" which is the basis for structuring the organizational and managerial component of the content of the formation of the OCS. The purpose of studying the discipline in question is the formation of students' knowledge and skills on the creation, functioning and improvement of the occupational safety management system at the enterprise, in institutions and organizations. When structuring the content of the special course, we took into account a systematic approach to building an occupational safety management system proposed by the International Labor Organization. The material of the special course is systematized into the following modules: the first module is "Occupational Safety Management as Quality Management of Occupational Safety"; the second module is "Psychological Aspects of Occupational Safety and Health Management". The first module reveals the theoretical and methodological foundations for the development, implementation and application of an occupational safety management system at an enterprise in the engineering industry, in organizations and institutions of the social sphere; the issues of informational and legal support of labor safety are considered. Students acquire knowledge about the types of planning and work forecasting on labor protection; labor safety control system; analysis and assessment of the state of labor protection. The second module is aimed at mastering the students' knowledge of the socio-psychological aspects of management. This module provides for the study of the following issues: the essence and tasks of psychological support for labor safety; psychological causes of industrial injuries; staff motivation; promotion of labor protection issues; safety culture.

An important type of professional activity of an occupational safety engineer is standard-setting which involves the development of draft local acts of an enterprise, organization, ensuring the creation and functioning of an occupational safety management system; review and revision of local acts of the enterprise on the ground of changes in labor protection legislation; support of the process of adoption and approval of regulatory legal acts with labor protection management bodies and public control over labor protection; development of employees' knowledge and skills in the field of safe implementation of professional activities. In view of the listed functions of the professional activity of an occupational safety engineer, it is important that in the process of structuring the content of the OCS we consider the standard-setting component that will be implemented through the content of the discipline of "Legislative and Legal Foundations of Safety" that purposes at forming legal knowledge and practical skills in applying legislative and regulatory requirements in the field of labor protection, which are the basis for creating safe and comfortable working conditions, and developing measures to protect people from negative factors of the working environment. The course involves the study 
of international principles of security; the main directions of state policy in the field of labor protection, international safety standards (conventions, protocols, and recommendations of the International Labor Organization); labor safety standards systems. The discipline of "Legislative and Regulatory Basis of Safety" is aimed at covering the following topics: legislative acts in the field of labor protection, duties and responsibilities of employees and officials to comply with legal requirements; specifics of labor regulation of individual professional groups, organization of the safety and labor protection management system, social partnership between employers and employees in the field of labor safety and protection, labor protection regulations, state regulation in the field of labor protection, legal framework and basic methods of regulation in the field of labor protection and production safety. As part of the study of this discipline, the questions of labor legislation are raised, the preparation of an employment and collective agreement, the implementation of internal labor regulations, documentation of the occupational safety and health.

Most of a person's life-sustaining activity is associated with the workplace where conveniences and comfortable conditions must be provided for effective labor productivity, as well as requisites to good health. In the "man-machine-environment" system, workers are influenced by harmful and dangerous factors of the working environment, the ergonomics of the workplace, the psychological and functional state of a person, and the psychological climate in the team. In view of this, the role of the labor culture as a combination of ergonomic and psychological knowledge and skills for the safe organization of the workplace and work space is increasing. Adhering to the above provisions, when structuring the content of the formation of OSC, we provided for the ergonomic component presented through the content of the academic disciplines such as "Workplace Ergonomics" and "Psychology of Occupational Safety". The discipline "Workplace Ergonomics" is aimed at developing students' holistic understanding of the ergonomic features of the work process, methods and ways of creating comfortable and safe working conditions while organizing the workplace and work space. The course examines the methods and technical means of ergonomics, the historical prerequisites for the emergence and development of disciplines on human factor integration. In addition, the discipline reveals the basic information about anthropometry, identifies the functions of interaction between man and machine, displays the principles of ergonomic support for the development of man-machine systems. When studying the course, the most important questions from the standpoint of ergonomic knowledge and skills are topics containing the concepts of "visibility zone", "motor space", "reach zone", "easy reach zone", "standing or sitting workplace", "working posture". It should be added that the course lays the foundations for developing the skills and abilities of applying the rules of anthropometric data accounting when calculating the ergonomic parameters of workplaces, methods for assessing the convenience and discomfort of a working posture, the vector-coordinate method for assessing a workplace. At the same time, discipline contributes to the development of skills in creating engineering projects that provide for the analysis of working conditions of various professions or a production facility and, on its basis, the development of a system of measures to optimize workplaces, work space, as well as improve labor safety. The interconnecting link in the ergonomics of the workplace is the academic course of "Occupational Safety Psychology" which studies the psychological aspects of human labor activity, the psychological causes of accidents arising in the labor process, psychological methods and means of improving occupational safety. The program of the discipline provides students with the knowledge about the causes and consequences of industrial injuries, problems of interaction between man and technology, psychological factors of labor efficiency and labor safety, mental regulations of labor activity. The course provides an opportunity to 
introduce students in more detail to the psychological foundations of labor activity and the behavior of a worker in the labor process, the psychological aspects of improving performance and organizing the workplace. In the course of the presentation of the course, it is important to pay attention to the concept forming terms of "working capacity", "monotony of work", "phases of fatigue", "professional stress" which constitute the basis of the course. In addition, within the framework of mastering the course, questions related to the study of the functional state of a person in work and human behavior in extreme situations are raised. It is important to note that the course lays down organizational, managerial, psychological and communication skills regarding the application of the principles of psychological management of a work collective, the methods and style of occupational safety management in an organization, the principles of managerial communication, psychological principles of intragroup interaction and creating psychological climate in a team; the theory of labor motivation management.

Article 1 of the Law of Ukraine "On Labor Protection" (1992) defines that labor protection is a system of legal, socio-economic, organizational and technical, sanitary-hygienic and therapeutic-prophylactic measures and means aimed at preserving life, health and working capacity a person in the process of labor activity. In addition, Article 6 of the Law of Ukraine "Fundamentals of the Legislation of Ukraine on Health Care" (1992) establishes that every citizen of Ukraine has the right to health protection that provides for: a standard of living, including food, clothing, housing, medical care and social services and provision which are necessary to maintain human health, a safe environment for life and health, sanitary and epidemic welfare of the territory and settlement where a person lives; safe and healthy working conditions, education, life and rest. Taking into account the requirements of the legislation regarding health protection, as well as aiming to form the health culture as a structural component of OSC, we consider it necessary to include the health-preserving component in the content of OSC formation which provides for the mastery by students of biomedical knowledge about methods and means of preventing general and occupational diseases, ways to promote health, expressed by a careful attitude and a conscious desire to preserve their own health. In the process of analyzing the curriculum, we came to the conclusion that it is advisable to implement the special course of "Medical and Biological Basics of Safety", the purpose of which is to update students' ideas in the field of interaction of the human body with environmental factors, on the medical and biological consequences of exposure to harmful and dangerous factors of human environment, about its sanitary and hygienic regulation. Based on the definition of the concept of "health" as a state of complete physical, psychological and social well-being of a person, we have found that the construction of the discipline "Medical and Biological Basics of Safety" must be carried out in the following logical sequence: the main indicators of human health, the concept of human health (somatic, psychological, moral health); the basics of health legislation; rights and obligations of citizens in the field of health protection; basics of health organization; ensuring healthy and safe living conditions; factors (psycho-emotional tension, stress, environmental factors, food quality) that affect human health; the impact of harmful substances and physical factors on human health; the impact of alcohol and drugs on human health; organization of human labor when working with a personal computer; the impact of electromagnetic fields, noise and vibration on human health; physiological parameters that determine the comfortable state of a person; heat exchange between a person and the environment; basics of hygienic regulation; human interaction with the environment; organizational medical and preventive measures to preserve human health; first aid in various life situations.

In accordance with the Model Regulations on the Procedure for Conducting Training and Testing of Knowledge on Occupational Safety (2005), the Model Regulations on Labor Protection Service (2004), the occupational safety engineer conducts induction on labor protection, 
coordinates the initial, repeated, unscheduled and targeted trainings, organizes advanced training and knowledge testing on labor protection issues, provides methodological assistance to heads of structural units in the development of training programs and instructions for labor protection, controls the conduct of labor safety briefings and internships in accordance with regulatory requirements. The foregoing emphasizes the need for an occupational safety engineer to master a pedagogical culture including the ability to structure and select educational material, to choose rational methods, forms, means and technologies for teaching occupational safety issues; to develop monitoring and measuring materials for labor protection. In addition, in the process of fulfilling the job duties, an occupational safety engineer is in constant interaction with the employer, employees, heads of structural divisions of the enterprise, state service of supervision and control over occupational safety, medical organizations where employees undergo medical examinations, and training centers where officials of a company faces undergo professional development in labor protection. This determines the importance of developing communication skills among occupational safety engineers, manifested by the presence of oratorical abilities and charisma in order to convince and motivate employees to comply with labor protection requirements, to increase the interest of workers in improving working conditions, and to involve them in solving problems related to labor safety. The above provisions stipulate the importance of designing the communicative component in the content of the formation of the OSC which is realized through the selection and structuring of the disciplines such as "Business Communications" and "Pedagogy of Safety". Thus, the purpose of studying the course of "Business Communications" is to acquire theoretical knowledge and the necessary practical skills in business communications including personal communication culture and the ability to communicate with the team to achieve productive activities, create the favorable moral atmosphere, and the ability to negotiate with partners. The course program acquaints students with the main stages of the development of communication theory, the methodology of studying the communicative space of communication theory in the system of sociological knowledge, the structure of the communication process, models of mass communication, communication channels and types of communication. In addition, the course lays down the skills of leading oral business communications, the psychological characteristics of public speaking, the peculiarities of the implementation of written business communications, communication management methods. The purpose of studying the following course of the communicative component such as "Pedagogy of Safety" is to assist in the formation of a graduate's readiness to master multifunctional professional competence in the field of teaching labor protection and technosphere safety. The course reveals the theory of teaching labor protection and technosphere safety; methods and means of teaching labor protection and technosphere safety; forms of organization of training on labor protection and technosphere safety; methods of analysis and assessment of the educational activities of students. The discipline under consideration teaches students to understand the problems associated with the procedure for organizing training and testing knowledge on labor protection, the procedure for developing training programs on labor protection and various types of instructions on labor protection, methods of popularizing labor protection issues. A key place in structuring the content of this course is devoted to modern information technologies in the process of teaching labor protection issues, types of software products in the field of labor protection, video instructions on labor protection, studying the automated workplace of an occupational safety and health engineer. 


\section{Conclusions}

Thus, a clear scientific substantiation of the content and its design should ensure the effectiveness and efficiency of the formation of the occupational safety culture among future occupational safety and health engineers. The proposed structuring of the content of formation of culture of occupational safety among future occupational safety and health engineers was carried out for the Bachelor's educational qualification level. The next step of our research is the development of the content of the formation of the culture of occupational safety among future occupational safety engineers for the Master's educational qualification level that will be implemented through the introduction of a special course "Occupational Safety Culture". In turn, this will contribute to the implementation of such didactic principles as the continuity and integrity of training at all stages of the professional training of occupational safety and health engineers. In the future, our research requires consideration of methods, forms and means of forming the culture of occupational safety of professional activity in future occupational safety and health engineers based on the content designed.

\section{References}

Zakon Ukrainy «Pro okhoronu pratsi» (1992) [Law of Ukraine “On Labor Protection”]. № 2694-XII rozd. I st. 1. [in Ukrainian]

Zakon Ukrainy «Osnovy zakonodavstva Ukrainy pro okhoronu zdorovia» (1992) [Law of Ukraine "Fundamentals of the Legislation of Ukraine on Health Care”]. № 2801-XII rozd. II st. 6. [in Ukrainian]

Typove polozhennia pro poriadok provedennia navchannia i perevirky znan z pytan okhorony pratsi ta Pereliku robit z pidvyshchenoiu nebezpekoiu (2005) [Model Regulations on the Procedure for Training and Testing of Knowledge on Occupational Safety and the List of High-risk Work]. № 15. [in Ukrainian]

Typove polozhennia pro sluzhbu okhorony pratsi (2004) [Model Regulations on Labor Protection Service]. № 255 [in Ukrainian] 